\title{
DETECTING TRENDS IN TROPICAL RAINFALL CHARACTERISTICS, 1979-2003
}

\author{
K. M. Lau and H. T. Wu \\ Laboratory for Atmospheres \\ NASA/Goddard Space Flight Center \\ Popular Summary
}

The recent scientific debate on the relationship between increased hurricane intensity, such as Katrina, and global warming, stems mainly from the difficulty in detecting long-term trends from short-term climate records. It is noteworthy that this debate is raging on, amidst a backdrop of anecdotal evidences of increasing occurrence of a myriad of extreme weather and climate events from flash flood in East Asia, extreme heavy monsoon rainfall in South Asia, prolonged drought in Africa, and severe cold winters in North America, devastating heat wave and flooding in Europe, to reduction in cloud amount in the tropics, and radar observations of different drop size distributions in rainfall in the Asian Pacific. Are these changes real? Why are they showing up now? Do they happen just by chance? Or are they telling us about fundamental changes in our climate system. So far no studies have been able to connect all these changes in a coherent way

In this paper, we address the issue of extreme weather from the point of view of trends of rainfall characteristics, i.e., extreme light, intermediate to extremely heavy events, in the tropics. Because more than half of the total area of the tropics is covered by oceans, quantitative rainfall estimates have to rely on satellite observations. However, satellite rainfall estimates have inherent large errors, because of uncertainties in the retrieval algorithms. For multi-decadal datasets, the problem is compounded by the amalgamation of data from different satellites which have different orbits, instruments and retrieval algorithms, that have to be merged to produce the longterm record.

We use two state-of-the-art global multi-decadal rainfall data set to examine the long-term trend of rainfall characteristics in the tropics: The Climate-Prediction Center (CPC) Merged Analysis of Precipitation (CMAP) and the Global Precipitation Climatology Project (GPCP). In addition, we use the NASA TRMM dataset to provide interpretation of the results. Both the CMAP and GPCP are subject to the aforementioned problems regarding merged satellite data products. Using the concept of probability distribution function (PDF) which, simply put, is a measure of the rainfall amount as a function of the rain rate over the entire tropics, we find that the two data sets are quite consistent in showing : a) a relatively uniform increase in light (warm) rain over the tropical oceans, b) an increase in extreme heavy (ice-phase) rain over the near-equatorial oceans, and c) a reduced moderate (mixed-phase) rain over the tropical ocean and land regions. This means that instead of one, there are three distinct, highly detectable trends in tropical rainfall captured by both data sets. But because the exact amount of change with each trend differs between the two data sets due to measurement errors, the total tropical rainfall trend is still undetectable.

The results of this paper are paradigm shifting in demonstrating that global satellite rainfall datasets have come of age, and can be used. meaningfully to detect trend signals in tropical rainfall. The results also provide new evidence indicating rainfall characteristic may be sensitive to global change, more so than the rainfall total. This paper also features a discussion on how microscopic changes in one end of the rain spectrum, i.e., drizzle, may need to be compensated by changes in the heavy downpour at the other end of the spectrum. This may explain from a total system viewpoint, why increased extreme heavy rain events, i.e., those associated with hurricanes, may be a likely response in a warmer climate. 


\title{
DETECTING TRENDS IN TROPICAL \\ RAINFALL CHARACTERISTICS
}

DURING 1979-2003

\author{
K. M. Lau and H. T. Wu ${ }^{*}$ \\ Laboratory for Atmospheres \\ NASA/Goddard Space Flight Center \\ Greenbelt, MD 20771
}

November 2005

* Science and Systems Application Inc., Lanham, Maryland 


\begin{abstract}
From analyses of blended space-based and ground-based global rainfall data, we found increasing trends in the occurrence of extreme heavy and light rain events, coupled to a decreasing trend in moderate rain events in the tropics during 1979-2003. The trends are consistent with a shift in the large-scale circulation associated with a) a relatively uniform increase in warm rain over the tropical oceans, b) enhanced ice-phase rain over the nearequatorial oceans, and c) reduced mixed-phase rain over the tropical ocean and land regions. Due to the large compensation among different rain categories, the total tropical rainfall trend remained undetectable.
\end{abstract}

One sentence summary: We found significant shifts in tropical rainfall characteristics identified with an increase in the frequency of heavy and light rain events, and a decrease in moderate rain events, but no detectable trend in total rainfall over the tropics during the period 1979-2003. 


\section{Introduction}

All water that sustains life on Earth ultimately comes from precipitation. Latent heating from precipitation is the main driver of the atmospheric water cycle, which determines earth's weather and climate. Yet, contrary to the well-documented rapid rise in global temperature in the last century, there has not been clear evidence of associated change in global precipitation (1-3). Recent studies have shown an increase in precipitation over high-latitude land, and a possible increase over the tropical oceans but a reduction over tropical lands since the 1950's (4-6). Over oceans where rainfall estimates rely on satellite observations, the uncertainty in the estimate of total rainfall is large. Since about two-third of the world is covered by oceans, the lack of reliable oceanic rainfall estimates for long-term signal detection is a reason why no global rainfall trend associated with climate change has been yet detected. A more fundamental reason, however, is that rainfall is a chaotic quantity governed by non-equilibrium atmospheric dynamics and convection, in contrast to temperature, which is a state variable subject to equilibrium thermodynamical controls. This accounts for the intrinsic small scale and noisy nature of rainfall, and hence the low signal-to-noise ratio relative to temperature in climate change studies. Globally, the latent heat increase from enhanced convection and increase rainfall in one region has to be balanced by radiative cooling in clear regions elsewhere with compensating subsidence and suppressed rainfall. This means that in response to long-term climate forcing, the global water cycle is likely to adjust not only dynamically, but also structurally and this will be reflected in changes in rainfall characteristics, such as frequency of occurrence of intense events, persistence of wet and dry spells, and changes in relative abundance of cold vs. warm rains, high vs. low cloud 
types $(4,7-10)$. As a result, the trend in global total rainfall is likely to be relatively small and probably within satellite data errors. Even with the recent advances in space-based rainfall measurements from the Tropical Rainfall Measuring Mission (TRMM), and the reconstruction of state-of-the-art global datasets merging satellite and rain gauge observations, estimating global rain amounts remains a major challenge.

In this study, we adopt a new strategy for the detection of long-term rainfall changes using existing data. We hypothesize that (a) a shift in rainfall probability distribution function (PDF) associated with changing rainfall characteristics is likely to be more sensitive to climate change than the global mean total rain amount, and hence more detectable, and (b) current multi-decade merged satellite-gauge rainfall products contain useful information on long-term change in rain characteristics, even though they may differ in the assessment of total rain amount. We will focus on tropical rainfall, because that is where most of the global rainfall occurs, and because tropical rainfall estimates have seen significant improvements in the last decade and will continue to do so in the next decade, thanks to NASA's commitment to TRMM and the Global Precipitation Mission (GPM).

\section{Data description}

For this study, we use two popular, state-of-the-art multi-decade (1979-present) global rainfall data sets: the Global Precipitation Climatology Project (GPCP), and the Climate Prediction Center (CPC) Merged Analysis of Precipitation (CMAP). Both have monthly and pentad (5-day) products derived from a mix of satellite estimates over ocean and land, rain gauge measurements from land and atolls, although the input data and 
blending methodologies differ considerably (e.g., 11-13). We elect to use the GPCP and CMAP pentad products to allow for more samples to define rainfall characteristics temporally. The pentad CMAP data are produced similarly to the monthly CMAP, but include daily data inputs. The pentad GPCP is derived from the pentad CMAP, but additionally adjusted to the monthly GPCP-merged analysis and therefore has the same long-term mean properties as the monthly GPCP (12-13). Because of the use of multiple satellites and different retrieval algorithms, the use of these datasets for trend analysis has to be taken with significant caution (12). We conducted identical analyses on both GPCP and CMAP. For cross-checking results over land, we use the long-term Hadley Centre Climate Research Unit (CRU) Time Series 2.0, global gridded land precipitation products (14). For discussion, TRMM storm height data are used to define the rainfall characteristics.

\section{Results}

We define a trend empirically as the linear regression fitted to the data for the period 1979-2003. We caution that this definition does not necessarily imply a "real trend" in the sense of long-term climate change (century) time scale. Here the trend only represents a monotonic shift, which may be a part of a multi-decadal signal present in the climate system.

\section{a. Preliminary Trend Analysis}

Figure 1 shows the time history of tropical $\left(30^{\circ} \mathrm{S}-30^{\circ} \mathrm{N}\right)$ pentad rainfall for GPCP and CMAP. A 30-day running mean has been applied to both datasets to emphasize the low-frequency variability. The discrepancy between GPCP and CMAP is obvious. The 
long-term (1979-2003) mean rainfall of GPCP $\left(2.9 \mathrm{~mm} \mathrm{day}^{-1}\right)$ is significantly smaller than that of CMAP (3.3 mm day $\left.{ }^{-1}\right)$ CMAP shows a clear decreasing trend compared with GPCP which shows a slight increasing trend. The trend found in CMAP is known to be contaminated by artifact due to discontinuity in inclusion of SSM/I data after 1987, and a change of quality of atoll data after 1996 (12). These account for the shift in the apparent rainfall variability before and after 1987, and the closer agreement between CMAP and GPCP after 1996 (GPCP does not use atoll data). In spite of the systematic bias, and difference in the trend, both dataset capture major rainfall peaks associated with El Nino, e.g. 1982, 1985, 1987, 1997, and exhibit strong interannual and some interdecadal variations, albeit with different phases. Comparing with standard TRMM rainfall products (not shown), we also note that the systematic bias between the tropical mean GPCP and CMAP is comparable to that between Version 5 and Version 6 of the TRMM rainfall data. Thus, the global trend in total rainfall, if present at all, is most likely within the data error of current satellite estimates. Clearly, to extract useful information on long-term change in rainfall, it is necessary to go beyond comparing global trends in total rainfall.

As a first step in our new approach, we examine changes in extreme rain events. For convenience, we shall henceforth denote extreme light rain as the category at the lowest $5 \%$ rainfall accumulation (B5), extreme heavy rain as the top $10 \%$ (T10), and rainfall within the inter-quartile range as the intermediate rain (I25). From Table 1, it is evident that GPCP and CMAP describe similar rain characteristic in that for both datasets, the threshold value is the same $\left(=1 \mathrm{~mm} \mathrm{day}^{-1}\right)$ for $\mathrm{B} 5$, and the range and thresholds for I25 and T10 are similar. Figure 2 shows the time series of the yearly 
accumulated rain amount averaged over the tropics, and the frequency of occurrence (FOC) for the extreme light and heavy rain. In contrast to the total rainfall, both the GPCP and CMAP data indicate clear increasing trends, in both rain amount and FOC of extreme light, and heavy rain categories. Note that the trends in both light and heavy rains are more prominent after 1986, indicating that they are not due to the inclusion of SSM/I data. The linear trend estimates exceed the $99 \%$ confidence level based on the $\mathrm{R}^{2}$ test (15). Table 1 shows that for extreme light rain in the tropics, the long-term (25 year) annual mean is approximately $46 \mathrm{~mm}$ for GPCP and $49 \mathrm{~mm}$ for CMAP. Both show an increasing trend in annual rainfall of about $4 \mathrm{~mm}$ over 25 years. The corresponding increase in FOC is substantial, approximately $9 \%$ for CPCP, and $4 \%$ for CMAP. The increasing trend in annual rainfall in the extreme heavy rain category is quite large, estimated to be around $81 \mathrm{~mm}$ for GPCP, and $44 \mathrm{~mm}$ for CMAP over 25 years. The increasing trend in FOC of extreme heavy rain (Fig. 2D) is also evident in both datasets. It is important to note that extreme heavy rain events are very rare, as indicated by the FOC range of $0.8-1.8 \%$ (Fig. 2B), and that extreme light rains occur much more frequently and widely spread, as evident in the $33-45 \%$ FOC range (Fig. 2D). The physical implication of this difference on the water and energy balance of the tropics will be discussed in Section 4.

\section{b. Probability Distribution Function (PDF)}

The preliminary trend analysis for extreme rainfall categories suggests that there may be a shift in the rainfall PDF during the data period. To examine such a shift, we first bin the rainfall data according to rain rates, and construct the climatological rainfall 
PDF for the tropics for both GPCP and CMAP, and then compute by linear regression the trend for each binned rain rate. To reassure that the PDF and the estimated trend are not sensitive to the data period, we have computed them for the entire data period and for the post-SSM/I era (1988-2003). The results are essentially the same. Henceforth we only show results for the entire period (1979-2003). The climatological PDFs of GPCP and CMAP rainfall and FOC are shown in Figs. 3A and B, respectively. Compared to GPCP, CMAP overestimates rainfall in all categories, but maintains a very similar PDF structure (Fig. 3A). Both PDFs show a maximum at the intermediate range of $\sim 3-7 \mathrm{~mm}^{\mathrm{day}}{ }^{-1}$. The GPCP PDF tends to tail off toward high rainrates slightly faster than CMAP. The FOC PDFs (Fig. 3B) of GPCP and CMAP agree well with each other, showing that B5 occurs far more frequently $(\sim 40 \%)$ compared to all other rain events. The geographic distribution of FOC for each rain category also shows reasonable agreement between the two datasets. As shown in fig. S1, B5 rain is found over large expanse of the subtropical ocean, with relatively low sea surface temperature i.e., eastern Pacific and Atlantic, southeastern Indian Ocean, with frequent occurrence just off the west coast of continents, most likely in conjunction with coastal upwelling and stratocumulus clouds; I25 rain is found most frequently in the tropical warm pool regions, with strong signal over the land masses of central and western Africa, the maritime continent and Amazonia; T10 rain is found predominantly over the core convective region of the western Pacific, eastern Indian Ocean and the Pacific and Atlantic ITCZ.

To quantify the shift of the rainfall PDF, we follow the same procedure to compute the trend of rain amount, and FOC over the entire tropics $\left(30^{\circ} \mathrm{S}\right.$ to $\left.30^{\circ} \mathrm{N}\right)$ binned by rain rates. Figures $4 \mathrm{~A}$ and $\mathrm{B}$ show the linear trend increment of rain amount and FOC over 
the 25 year, with the data binned at the interval of $1 \mathrm{~mm}^{-1}$ day ${ }^{-1}$ Only trends that exceed the $95 \%$ confidence level are shown. Both PDFs show significant positive trends in B5 and $\mathrm{T} 10$, with a very pronounced reduction in $\mathrm{I25}$. The negative trend in GPCP is prevalent for rain rate $>1 \mathrm{~mm} \mathrm{day}^{-1}$ up to $14-15 \mathrm{~mm} \mathrm{day}^{-1}$, yet for CMAP the negative trend extends further to rain rate up to $20 \mathrm{~mm}^{-1}$ day $^{-1}$. This larger range of rain rates with negative trend in CMAP compared to the smaller range in GPCP explains the decreasing trend of the total rain amount observed in CMAP data, but not in GPCP (See Fig. 1). The increase in FOC of B5 is very pronounced in both datasets, with GPCP showing greater than $9 \%$ and CMAP $4 \%$ increase. The reduction in FOC of $\mathrm{I} 25$ is very clear. In contrast, the increase in FOC in T10 is barely noticeable in Fig. $4 \mathrm{~B}$, because of the extreme low FOC compared to those of B5 and I25. However, in terms of fractional increments (normalized by the climatological mean for each rain rate bin) the trend in FOC becomes substantial in all three categories, and most pronounced in T10 (Fig. 4C). It is clear that the more extreme is the rain rate, the stronger is the fractional increment signal, indicating that the very intense rain systems are most affected by the trend.

\section{c. Spatial Pattern of Trends}

We examine the spatial distribution of the linear trend increment for B5, T10, I25 and total rainfall in this subsection. Here, the increments are computed as the accumulated rainfall for 1991-2002 minus that for 1979-1990, separately for GPCP and CMAP. Since the two datasets show qualitatively similar spatial distribution, only GPCP are shown in Fig. 5 to focus the discussion. Maps similar to Fig. 5 but for CMAP are shown in fig. S2. 
Fig. 5A shows that, in recent decade (1991-2002) compared to previous (19791990), there is an somewhat uniform increase in B5 rainfall over all tropical oceans, with noticeable reduction at the areas off the west coast of continents, the subtropical continental regions, and the maritime continent. The quasi-uniform pattern of the longterm change in B5 rainfall over the ocean suggests that the increase may be thermodynamic in origin, i.e., possibly due to the increasing warm rain efficiency associated with shallow clouds, associated with global temperature rise, which is not strongly affected by changes in large-scale circulation (9). In agreement with the PDF analysis shown previously, I25 (Fig. 5B) shows reduction over a wide swath of the tropical oceans, in broad regions encompassing the Pacific and Atlantic ITCZ, the subtropics, and the eastern Indian Ocean. Exceptions are found over the maritime continent, and northwestern South America where I25 is enhanced. As stated, B5 rain is actually found to decrease over the maritime continent. Hence the opposite polarity of long-term trend between B5 and I25 appears to hold up over the maritime continent as well. Figure $5 \mathrm{~B}$ also shows a large negative trend over equatorial central Africa. This trend is also found in CMAP (see fig. S2B), but is not observed in the analysis of CRU data (see discussion in Section 3d).

The trend pattern in Fig. 5C shows that $\mathrm{T} 10$ rainfall over the tropical oceans generally increases over the decades, consistent with PDF shift. The most pronounced positive trends are found in deep convective cores in the ITCZ, and SPCZ, and in landanchored monsoon depressions. Substantial reductions in T10 are found over the maritime continent, equatorial Central America and northeastern Brazil, and to a lesser extent over central Africa. The concentrated regions of large positive and negative 
anomalies reflect the centers of rising and sinking motion of an anomalous Walker Circulation. This feature is also evident in the total rainfall trend (Fig. 5D). However, comparing to the total rainfall trend (Fig. 5D), it is clear that each of the major rain categories show a more uniform increase or decrease over the entire tropical oceans, indicating a substantial change in the large-scale circulation, as well as a change in the rainfall characteristics, associated with a long-term large-scale adjustment in the tropical water cycle (see more detailed discussion in Section 4).

\section{d. Comparison with independent data}

In this subsection, we seek corroboration of our results with independent long-term rainfall dataset. Since there is no other independent long-term rainfall dataset over the ocean besides GPCP and CMAP, we can only compare our results with the CRU rainfall which is based solely on rain gauge data over land. Because of different spatial and temporal scales of the GPCP (pentad, $2.5 \times 2.5$ degree spatial resolution), compared with CRU (monthly, $0.5 \times 0.5$ degree spatial resolution), the comparison presented here is rather crude. Fig. 5E shows the spatial distribution of the quasi-decadal change (19912002 minus 1979-1990) of CRU rainfall. Similarities in the large-scale pattern between the CRU and the GPCP (Fig. 5D) can be discerned, particularly over the tropical South America, regions in South Asia and equatorial Africa. The magnitudes of the anomalies differ between the two datasets, due in part to the different spatial and temporal resolutions, and the fundamental differences in satellite rainfall estimate compared to rain gauge observations (16). As noted, the negative anomaly over equatorial Africa seems to be excessive for GPCP, compared to CRU. 
To further quantify the comparison, we select large land regions between $20^{\circ} \mathrm{S}-$ $15^{\circ} \mathrm{N}$, where the anomalies are pronounced, based on GPCP (shown as rectangles in Fig. 5D). We then compute the fraction change in rainfall (1991-2002 minus 1979-1990) for B5, I25 and T10 with respect to each rain category over the regions, for GPCP and for CRU respectively (Fig. 6). Note that the fractional change of total rainfall is relatively small ( $10-15 \%)$, having the same sign in both datasets in all regions, except the equatorial central Africa (Fig. 6B). The fractional change is largest ( 20-50\%) in T10, and consistent between the two datasets in all selected regions. The fractional changes in I25 and in B5 are usually smaller and less consistent among the two datasets. The magnitude of the rainfall change due to B5 is found to be much smaller than I25 and T10 (see Fig. 5). On the other hand, the absolute change in $\mathrm{I} 25$ is comparable to T10 in both datasets. Since the trends of T10 and I25 tend to be opposite in sign and comparable in magnitude, the total rainfall trend appears as the small difference between two large terms, and hence very sensitive to the errors in the estimated trend. In regions where the two datasets disagree in total rainfall trend, for example, over equatorial central Africa (Fig. 6B), CRU depicts a small positive trend in total rainfall and in I25, but GPCP shows the opposite, even though they agree in T10. An examination of the time series of rainfall over equatorial central Africa (not shown) indicates that the large decrease in GPCP total rainfall (due mostly to I25) stems from a major negative shift since 1987, suggesting the possibility that the decrease may be an artifact related to the inclusion of SSMI data, which may have adversely impacted the land rainfall estimate in GPCP over Africa. Over the maritime continent, CRU shows negligible fractional change in total rainfall, but GPCP shows a small negative fractional change. However, both datasets are 
consistent in showing a strong fractional reduction in T10, and an increase in 125 , though the magnitudes differ considerably (not shown).

The GPCP estimate of the trend in total rainfall for the selected regions, except for central equatorial Africa, is likely more reliable than CRU because GPCP takes into account oceanic influences that are consistent with the decadal change of the large-scale circulation. On the other hand, the CRU data may reflect more local effects, and less of the large-scale circulation changes. Overall, the pronounced T10 relative changes in the two datasets are consistent in depicting a decadal shift in rainfall distribution, with regions of West Africa (Fig. 6A), northern Australia (Fig. 6D), and western equatorial South America (Fig. 6E) falling under the influence of the rising branch, and equatorial Africa (Fig. 6B), the maritime continent (Fig. 6C) and eastern equatorial South America (Fig. 6F) under the influence of the descending branch of an anomalous Walker Circulation (see also Fig. 5D). The results also agree with many previous observations of long-term trends in extreme regional precipitation in the climate record $(17,4$, and others).

\section{Further discussion}

Why are there such close relationships among the trends of light, intermediate, and heavy rainfall in the tropics? In this section we offer some food for thought and future work. First of all, as shown in previous studies (9-10), the extreme light, intermediate and extreme heavy rain events are mainly associated with warm (liquid phase), mixedphase, and cold (ice-phase) rain respectively. This association can also be seen in fig. S3 which shows the joint PDF of GPCP rainrate with collocated storm height from TRMM 
data. For B5 rain, the peak occurrence at found at $2-3 \mathrm{~km}$, below the melting/freezing level (MFL) near $5 \mathrm{~km}$; for I25, the peak is found near the MFL; for T10, the distribution is more heavily weighted above the MFL. Given the aforementioned association, the increase in light rain (B5) may be identified with increase in warm rain efficiency associated with the rise in sea surface temperature in all tropical ocean basins in the last several decades. As shown by Lau and Wu (9), the warm rain increase is due to thermodynamic and microphysical effects associated with shallow convection, and/or stratocumulus processes. They pointed out that the increased warm rain depletes low and middle clouds, and deprives the upper atmosphere of available moisture for condensation by deep convection. This may be a reason for the reduction in intermediate rain (I25) found here, and consistent with observations of large reduction of ISCCP (International Satellite Cloud Climatology Project) clouds, as well as an increase in outgoing longwave radiation in the last two decades (8). The substantial positive trend in light rain frequency and possible induced reduction in cloudiness are important for the overall energy balance of the tropics, because of the large area they occupy, i.e., greater than $40 \%$ of the tropical area as estimated from GPCP. For the tropics as a whole, an increased cooling (through heat loss) to space, due to the reduction of clouds stemming from an increase in warm rain over large regions, needs to be balanced by increased condensation heating elsewhere, generally over much smaller spatial scales because of the strong control by moisture convergence and local topographic uplifting . This may be the reason for the pronounced positive trend in intense rain (T10), located in deep convective cores of the ITCZ, SPCZ and the Indian Ocean, as well as increased intermediate rain (I25) in the maritime continent, and near steep topography of the Andes 
(see Fig. 5B). Locally, when penetrative deep convection occurs, the clouds are pushed to higher altitudes, ice-phase rain (T10) dominates and mixed-phase (I25) rain reduces, and conversely in regions where mixed-phased rain dominates. In addition, anomalous rising motions from increased convection over the central Pacific and the Indian Ocean are known to drive compensating subsidence, through Walker- and Hadley-type largescale overturning suppressing rainfall over the maritime continent and northern South America, and the subtropics. These anomalous overturnings can be inferred from Fig. 5D. Hence, the inter-relationship in the trends for extreme light, heavy and intermediate rains and their preferred locations may be understood in terms of the interplay of adjustment processes that involve dynamics and microphysics, as manifested in a spatial redistribution of rainfall and characteristics change of tropical rain systems. Such adjustment processes appear also to be captured in part in recent AGCM experiments as responses of the tropical water cycle to changes in autoconversion rates, to indirect aerosol effects, and in coupled model simulations from $20^{\text {th }}$ century simulation experiments $(10,18-19,7)$.

\section{Conclusion}

Using GPCP and CMAP pentad rainfall data, we have analyzed trends of rainfall characteristics for the entire tropics from 1979-2003. Although the linear trend signals for total tropical rainfall differ considerably, the changes in their PDFs are highly detectable, and qualitatively similar between the two datasets. Significant positive trends are found in extreme light (bottom $5 \%$ by rain amount) and extreme heavy rain (top $10 \%$, and negative trend are found in intermediate rain (inter-quartile range) categories. 
Extreme light rains are found to have increased more or less uniformly over the tropical oceans in the last two decades. Extreme heavy rain amounts and frequency of occurrence are found to be on the rise since the early 1980 's in the cores of deep convection in the ITCZ, SPCZ, the Indian Ocean, and monsoon regions, but reduced over the maritime continent. Intermediate rain amount is reduced over the warm pool regions, the ITCZ and SPCZ adjacent regions, but enhanced over the maritime continent. Both GPCP and CMAP show consistent and comparable spatial and temporal signals in linear trends for all three broad rain categories. The linear trends and inter-relationships among the various rain components are found to be robust, in spite of uncertainties in total rainfall. The shift in rainfall characteristics and the geographic redistribution of rain amount are determined by the interplay of dynamical and microphysical adjustment processes of the entire tropical convection and large-scale circulation system.

Our results show that while the atmospheric water cycle as measured by the longterm change in total tropical rainfall may be resilient to climate change because of large compensations, the structures of rain systems, especially the extreme rain events may be more sensitive to a warming environment $(20-22)$. The results will also provide a new paradigm for climate model evaluation. More modeling and observational studies should be devoted to document the changing characteristics of rainfall, and associated structural changes in the global water cycle. 


\section{References and Notes}

1. IPCC, Climate Change 2001: The Scientific Basis, Cambridge University Press, 870 pp (2001).

2. Karl, T., and K. E. Trenberth, Science, 302, 1719 (2003).

3. Allen, M. R., and W. J. Ingram, Nature, 419, 224 (2002).

4. New, M., M. Todd, M. Hulme, and P. Jones, I. Journal of Climatology, 21, 1899 (2001).

5. Kumar, A., F. Yang, L. Goddard, and S. Schubert, J. Climate, 17, 653 (2003).

6. Bosilovich, M. G., S. Schubert, and G. Walker, J. Climate, 18, 1591 (2005).

7. Meehl, G. A., F. Zweiers, J. Evans, T. Knutson, L. Mearns, P. Whetton, Bull. Am. Meteor. Soc., 81, 427 (2000).

8. Weilicki, B. A., T. Wong, R. P. Allen, A. Slingo, J. T. Kiehl, B. J. Soden, C. T. Gordon, A. J. Miller, S.-K. Yamng, D. Randall, F. Robertson, J. Susskind, and H. Jacobowitz, Science, 295, 841 (2002).

9. Lau, K. M., and H. T. Wu, Geophys. Res. Lett. 30, 2290 (2003).

10. Lau, K.M., H. T. Wu, Y. Sud and G. Walker, J. Climate (in press, 2005). 11. Yin, X., A. Gruber, and P. Arkin, J. Hydrometeorology, 5, 1207 (2004).

12. Xie. P., J. E. Janowiak, P. A. Arkin, R. Ader, A. Gruber, R. Ferraro, G. J. Juffman, and S. Curties, J. Climate, 16, 2197 (2003).

13. Adler, R. F., J. Suskind, G. Huffman, D. Bolvin,1 E. Nelkin, A. Chang, R. Ferraro, A. Gruber, P. Xie, J. Janowiak, B. Rudolf, UI. Shneider, S. Curtis, and P. Arkin, $J$. Hydrometeorology, 4, 1147 (2003). 
14. New, M., M. Hulme, P. D. Jones, J. Climate, 13, 2217 (2000).

15. Wilks, D.S., Statistical Methods in the Atmospheric Sciences. Academic Press, 160$176(1995)$.

16. Nesbitt, S. W., E. Zipser, and C. Kummerow, J. Appl. Meteorology, 43, 1016 (2004).

17. Groisman, P. Ya., R. W. Knight, D. R. Easterling, T. R. Karl, G. Hegerl, V. N.

Razuvaev, J. Climate, 18, 1326 (2004).

18. Wang, H. and K. M. Lau, Int. J. Climatology (in press, 2005).

19. Rotstayn, L., and U. Lohmann, J. Climate, 15, 2103 (2002.

20. Trenberth, K.E., A. Dai, R. Rasmussen, and D. B. Parsons, Bull. Amer. Meteor. Soc., 94, 1205 (2003).

21. Emannuel, K., Nature, 436, 686 (2005).

22. Webster, P. J., G. J. Holland, J. A. Curry and H. R. Chang, Science, 309, 1844 (2005).

23. This work is supported by the Tropical Rainfall Measuring Mission (TRMM) of the NASA Science Mission Directorate. Drs. Hailan Wang and K. M. Kim provided useful discussion and suggestions during the course of this work.

\section{Supporting Online Material}

www.sciencemag.org/

Figs $\mathrm{S} 1$ to $\mathrm{S} 3$ 


\section{Figure Captions}

Fig. 1. Time series of pentad GPCP (thick line) and CMAP (thin line) tropical mean rainfall from 1979-2003. A 30-day running mean filter has been applied to both datasets. The straight lines are obtained from linear regression based on each dataset.

Fig. 2. Time series of (A) yearly accumulated precipitation amount, and (B) frequency of occurrence (FOC) for light rain (bottom $5 \%$ by precipitation amount), and similarly for (C) and (D) but for heavy rain (top 10\% by rain amount), for GPCP (closed square) and CMAP (open circle) respectively.

Fig. 3. The climatological (1979-2003) PDF for (A) yearly accumulated precipitation amount, and (B) FOC, for GPCP (filled bar) and CMAP (outlined bar) respectively.

Fig. 4. Shift in PDF shown as linear trend increment over 25 years as a function of rain rate for (A) yearly accumulated precipitation amount, and (B) FOC; and (C) as in (B) except normalized by mean in each rain rate bin.

Fig. 5. Difference patterns (1991-2002 minus 1979-1990) showing quasi-decadal shift in accumulated precipitation amount for (A) B5, (B) I25, (C)T10 and (D) total rainfall for GPCP, and (E) total rainfall for CRU.

Fig. 6. Normalized change in area-averaged accumulated precipitation from 1979-1990 to $1991-2002$, in B5, I25, T10 and total rainfall for (A) west Africa monsoon region $\left(0-15^{\circ} \mathrm{N}, 0-15^{\circ} \mathrm{E}\right),(\mathrm{B})$ equatorial central Africa $\left(15^{\circ} \mathrm{S}-5^{\circ} \mathrm{N}, 20^{\circ} \mathrm{E}-30^{\circ} \mathrm{E}\right),(\mathrm{C})$ maritime continent $\left[10^{\circ} \mathrm{S}-5^{\circ} \mathrm{N}, 105^{\circ} \mathrm{E}-160^{\circ} \mathrm{E}\right]$, (D) northern Australia $\left[20^{\circ} \mathrm{S}-10^{\circ} \mathrm{S}\right.$, $\left.120^{\circ} \mathrm{E}-150^{\circ} \mathrm{E}\right]$, (E) equatorial western South America $\left[10^{\circ} \mathrm{S}-10^{\circ} \mathrm{N}, 70^{\circ} \mathrm{W}-60^{\circ} \mathrm{W}\right]$, and (F) equatorial eastern South America $\left[10^{\circ} \mathrm{S}-0,60^{\circ} \mathrm{W}-40^{\circ} \mathrm{W}\right]$, for GPCP (filled 
bar) and CRU (outlined bar) respectively. Here, the rainrate ranges for B5, I25, and T10 are defined based on rainfall over tropical land only. 
Table 1. Threshold rain rate, climatological rain amount, frequency of occurrence and linear change (mm) over 25 years (1979-2003) averaged over the tropics, for light, intermediate and heavy rain defined as the bottom 5\% (B5), inter-quartile range (125), and top 10\% (T10), respectively for a) GPCP and b) CMAP.

\section{(A) GPCP}

\begin{tabular}{|l|l|l|l|}
\hline & B5 & $\mathrm{I} 25$ & $\mathrm{~T} 10$ \\
\hline Threshold rain rate $(\mathrm{mm}$ day-1) & $<1$ & $(4,14)$ & $>20$ \\
\hline Mean amount $(\mathrm{mm})$ & 46 & 544 & 119 \\
\hline Linear change in amount $(\mathrm{mm})$ & 3.8 & -55 & 81 \\
\hline FOC $(\%)$ & 38 & 20 & 1.3 \\
\hline Linear change in FOC $(\%)$ & 9.4 & -2.2 & 0.8 \\
\hline
\end{tabular}

\section{(B) CMAP}

\begin{tabular}{|l|l|l|l|}
\hline & $\mathrm{B} 5$ & $\mathrm{I} 25$ & $\mathrm{~T} 10$ \\
\hline Threshold rain rate (mm day-1) & $<1$ & $(4,16)$ & $>23$ \\
\hline Mean amount $(\mathrm{mm})$ & 49 & 630 & 133 \\
\hline Linear change $(\mathrm{mm})$ & 4.2 & -88 & 44 \\
\hline FOC $(\%)$ & 39 & 22 & 1.2 \\
\hline Linear change in FOC $(\%)$ & 4.2 & -3 & 0.3 \\
\hline
\end{tabular}


Fig. 1

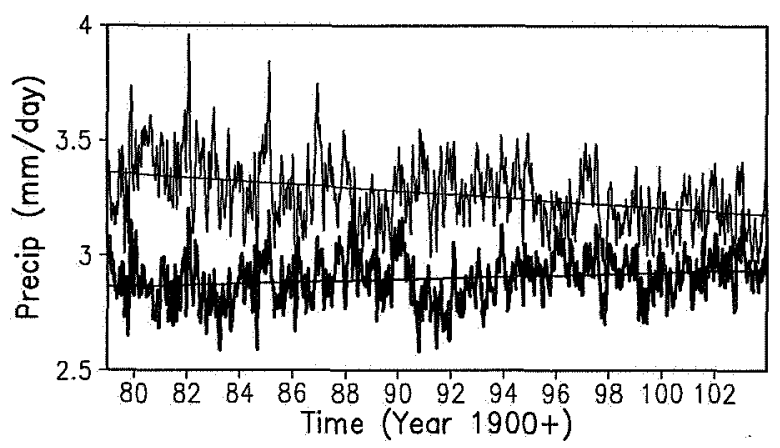


Fig. 2.
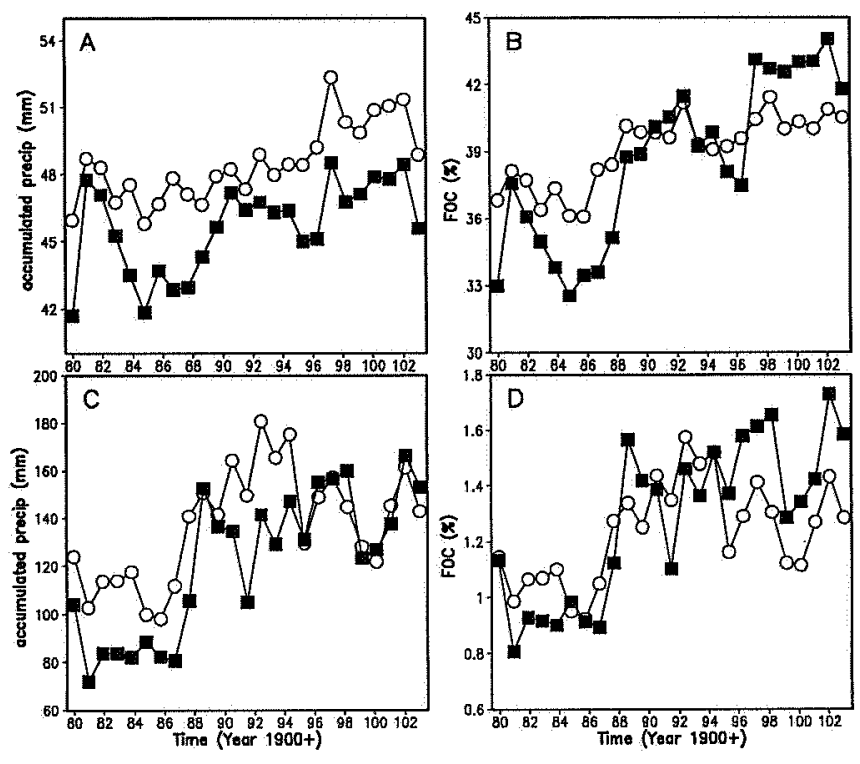
Fig. 3.

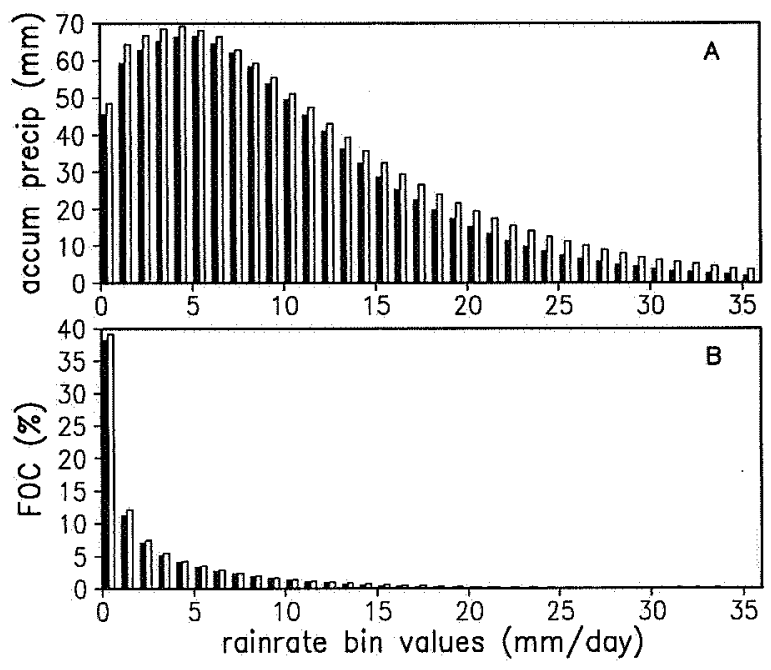


Fig. 4.

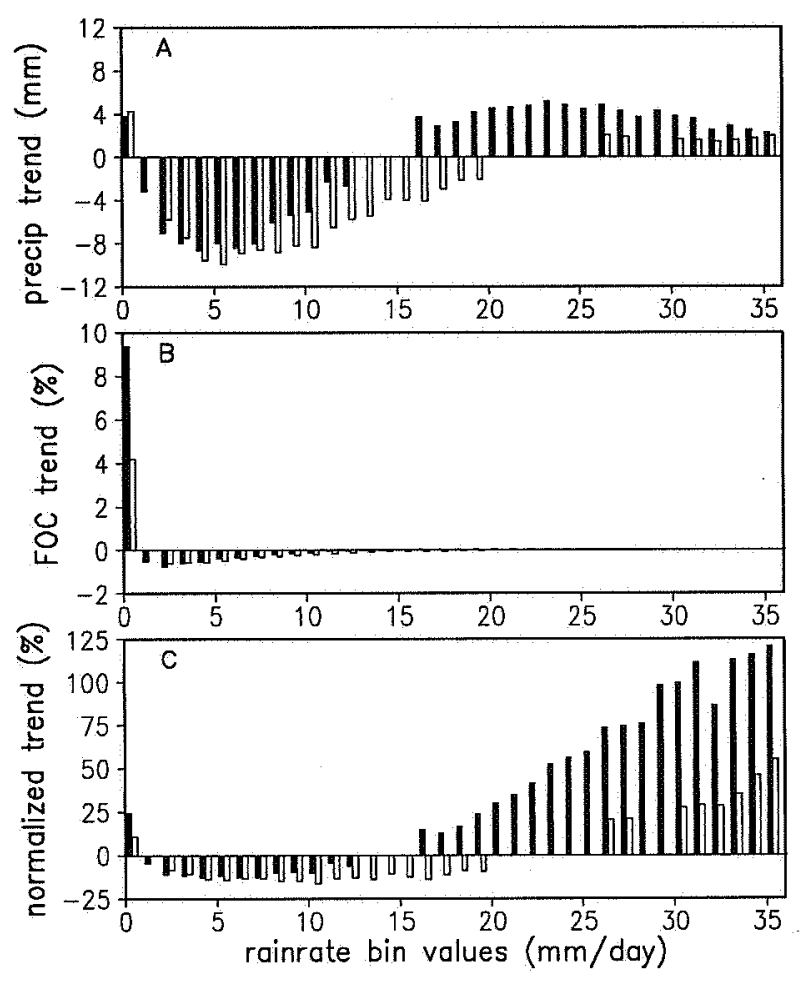


Fig. 5.
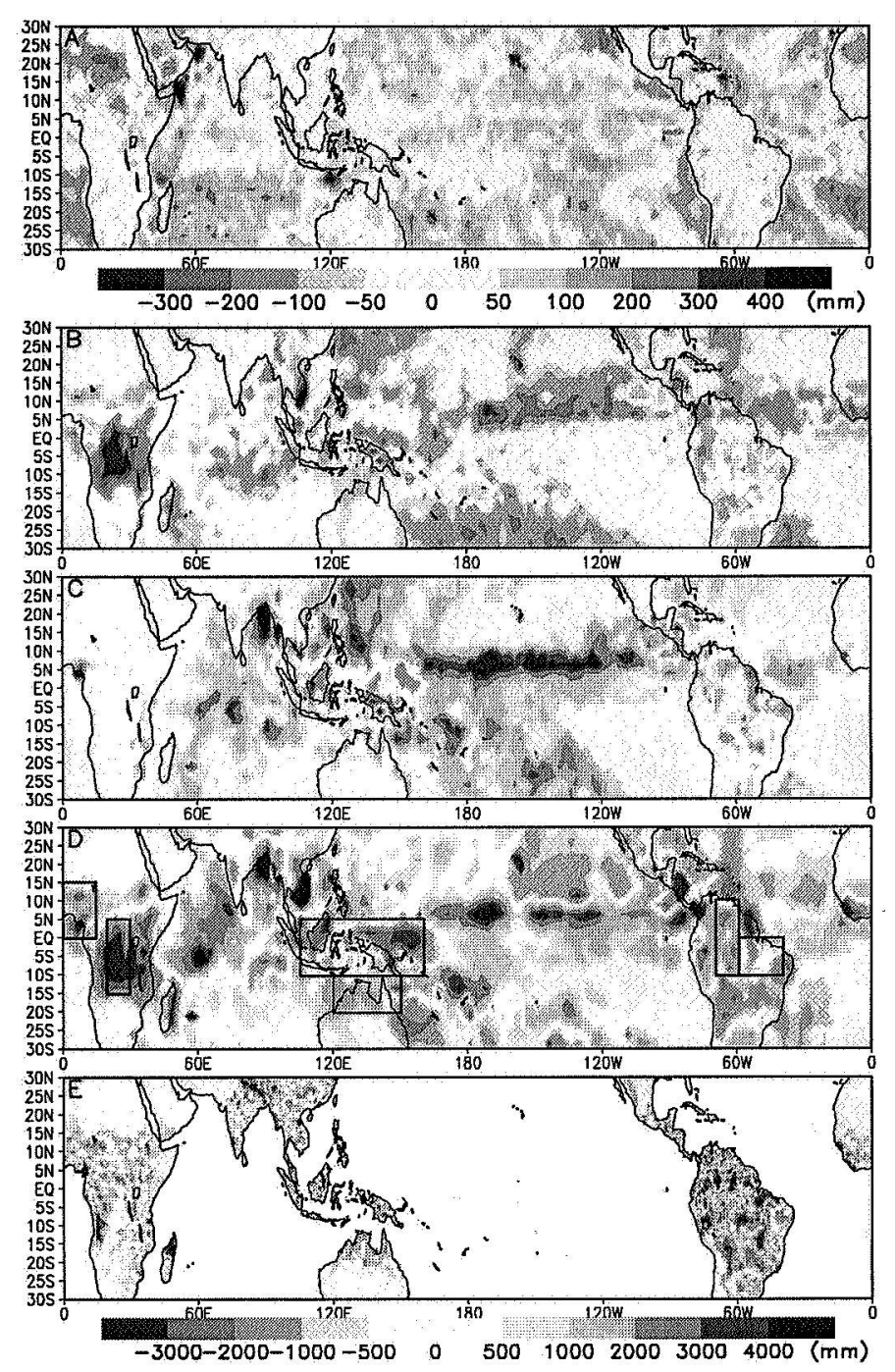
Fig. 6.

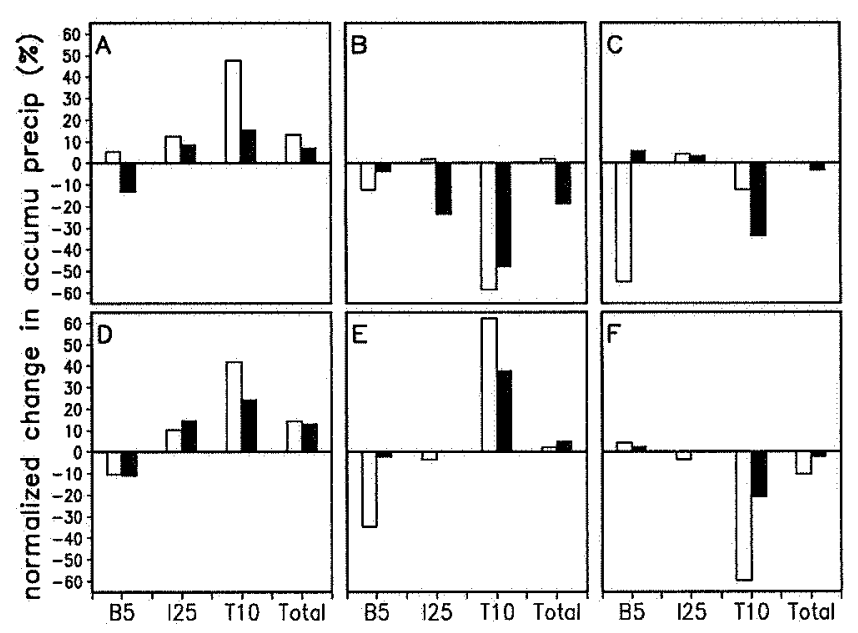



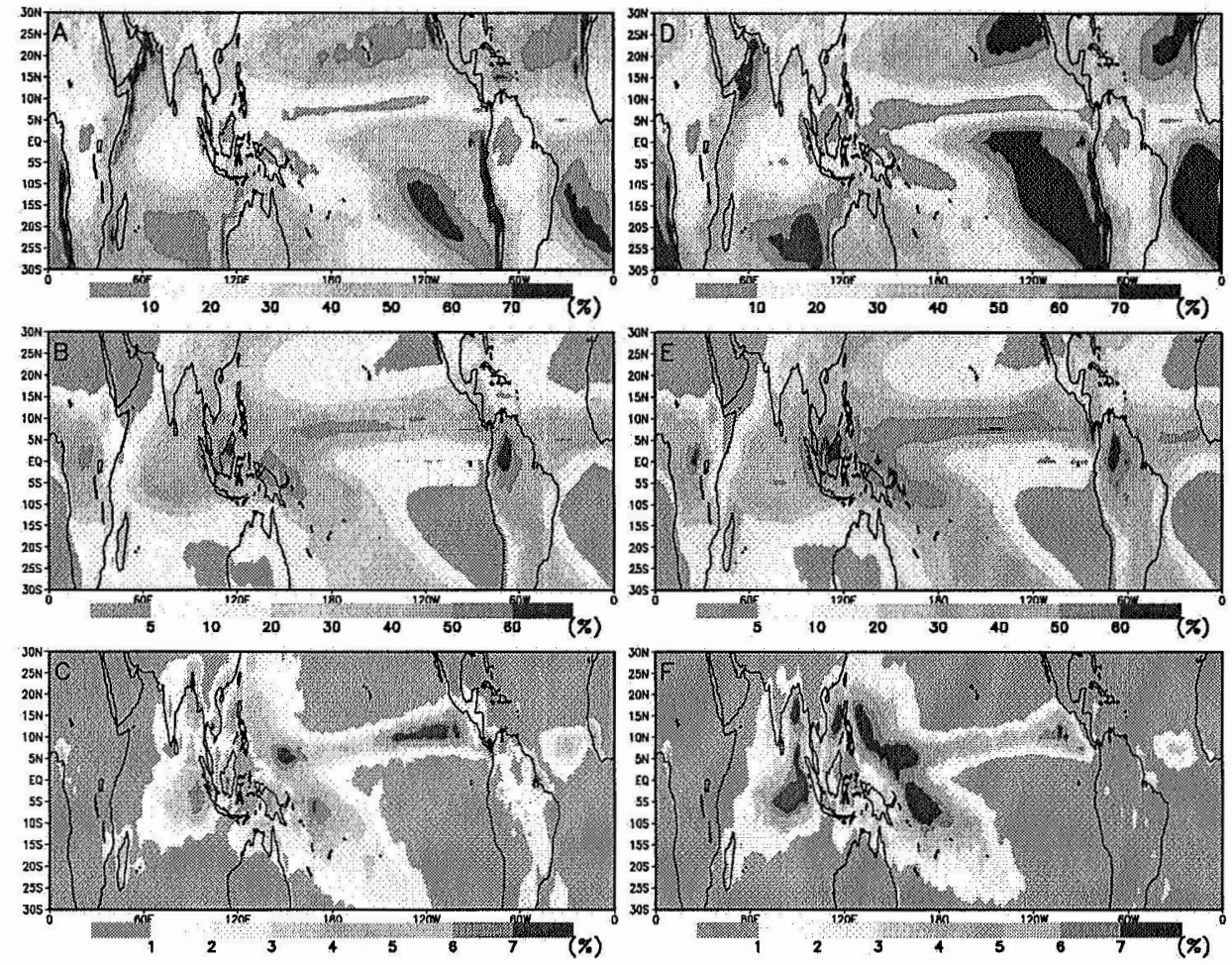

Fig. S1 Geographic distribution of FOC for different rain categories for (A) B5, (B) I25, and (C) T10 for GPCP and (D) B5, (E) I25 and (F) T10 for CMAP, showing that B5 occurs widely over the tropics, with maximum FOC in regions under the influence of the subtropical anticyclones of the Pacific, the Atlantic, and the southern Indian Ocean $(>50 \%)$. B5 is also prevalent in stratocumulus regimes off the west coasts of continent $(>70 \%)$, and along the coast of east Africa, and Saudi Arabia ( $>70 \%)$. The distribution of 125 resembles a mirror image of $\mathrm{B} 5$, with highest FOC over a wide swath covering the warm pool regions, the Intertropical Convergence Zone (ITCZ) and the South Pacific Convergence Zone (SPCZ). The maximum FOC $(>60 \%)$ for I25 is found over the tropical forests of Amazonia, the Maritime Continent and central Africa. Compared to B5 and 125, T10 occurs only rarely, with FOC greater than 5\% found in the core of the ITCZ of the Pacific and the Atlantic, and in deep convection anchored by the maritime continent, the Bay of Bengal, and land regions of monsoons of Asian-Australia, West Africa, Mexico and South America. 

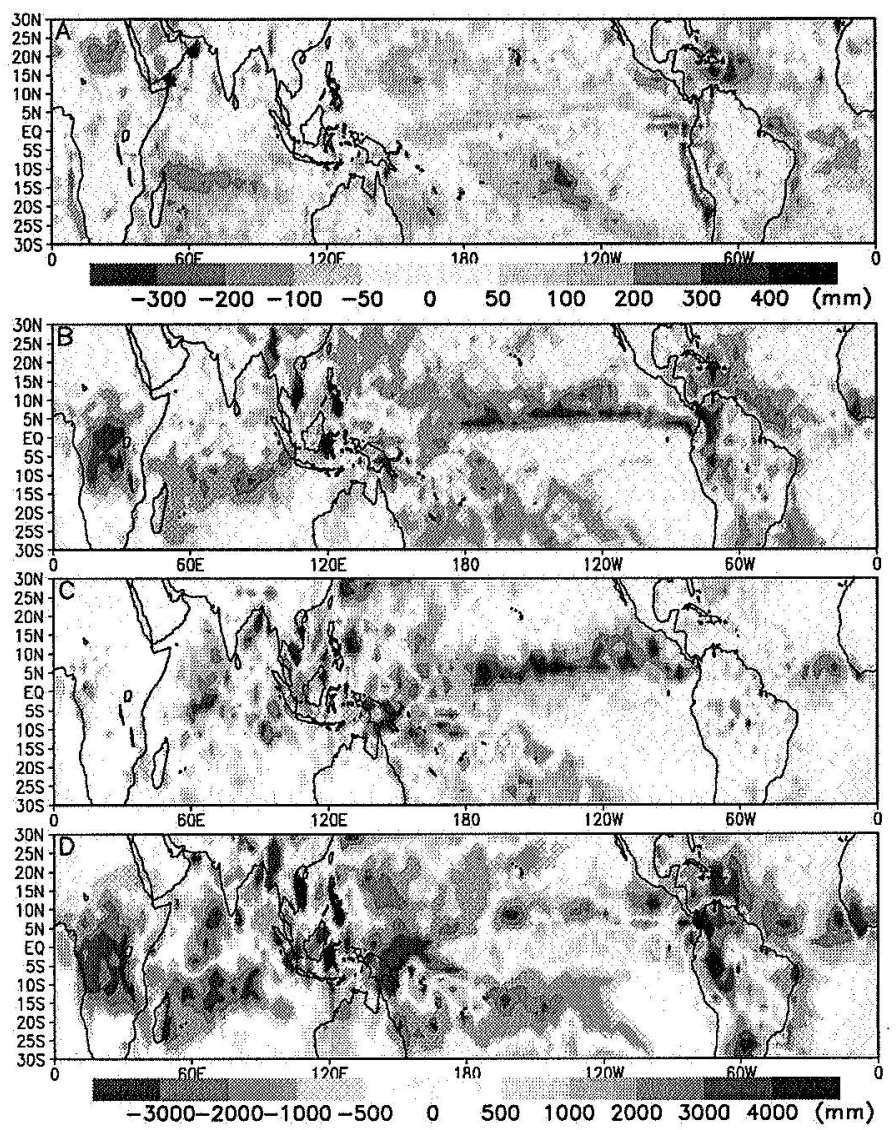

Fig. S2. Difference patterns (1991-2002 minus 1979-1990) showing quasi-decadal shift in accumulated precipitation amount for (A) B5, (B) 125, (C)T10 and (D) total rainfall for CMAP. 


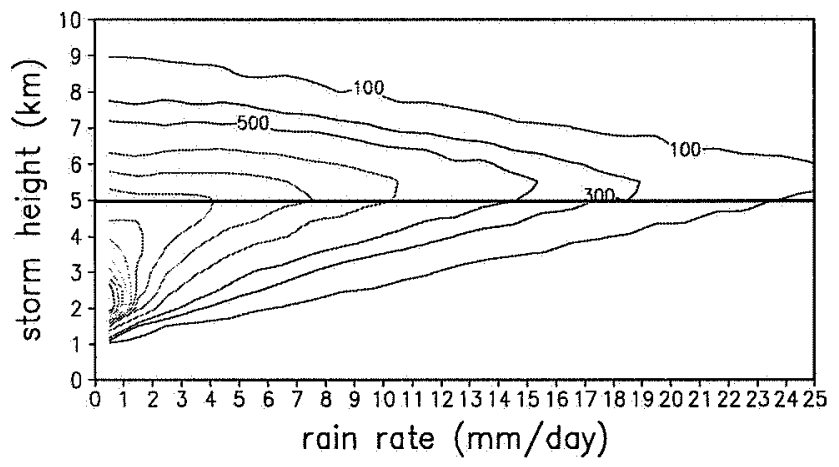

Fig. S3. Joint PDF of pentad rain rate from GPCP and storm height from TRMM data for 1998-1999, over the tropics $\left(30^{\circ} \mathrm{S}\right.$ to $\left.30^{\circ} \mathrm{N}\right)$. The mean melting-freezing level (MFL) at approximately $5 \mathrm{~km}$ is indicated by the horizontal line. B5 rain can be identified as primarily warm, water-phase rain, as evidenced by the peak concentration of B5 rain $\left(<1 \mathrm{~mm}^{\text {day }}{ }^{-1}\right)$ at $2-3 \mathrm{~km}$, below the MFL; I25 rain with rain rate between 4 $-14 \mathrm{~mm}$ day ${ }^{-1}$ is identified as mixed phase rain with approximately equal proportion above and below the MFL; T10 $\left(>20 \mathrm{~mm} \mathrm{day}^{-1}\right)$ is associated with cold, primarily ice-phase rain with a distribution weighted move above the MFL. 